\title{
Peramalan Penjualan Olein Curah di Perusahaan Pengolahan Kelapa Sawit Menggunakan Double Moving Average
}

\author{
Nurike Oktavia ${ }^{1}$, Alya Gustina ${ }^{1}$, Ridha Luthvina ${ }^{1}$ \\ ${ }^{I}$ Politeknik ATI Padang, Jl. Bungo Pasang-Tabing, Padang, 25171, Indonesia
}

\section{ARTICLE INFORMATION}

Received: November 10, 2021

Revised: December 15, 2021

Available online: December 31, 2021

\section{KEYWORDS}

Demand Planning, Forecasting, Olein

\section{CORRESPONDENCE}

Name: Nurike Oktavia

E-mail: oktavia.nurike@gmail.com

\begin{abstract}
A B S T R A C T
Bulk olein is one of the products produced by Palm Oil Processing Company. Bulk cooking oil controls 75 percent of the production market share in Indonesia and about 77.5 percent of households in Indonesia use bulk cooking oil because the price is cheaper than packaged cooking oil. Demand for olein in the future is predicted to be continued to increase, so it is necessary to estimate future sales so that production activities become more effective and efficient. The method used in this study is the double moving average (DMA), which is one of the forecasting methods with data that has a trend. The calculation will be done by comparing the result of 3 moving, 4 moving and 5 moving. Forecasting error is calculated using mean absolute percentage error (MAPE). The calculation results show that the average MAPE from DMA with 5 moving has the smallest value. To verify these results, an analysis of the processed data was carried out, namely looking for data with the furthest distance from the linear line, namely $t_{3}$ data and $t_{7}$ data. The data is omitted in data processing and then the MAPE error value is recalculated. The results obtained are that DMA with 3 moving results have the smallest error, which is 11.863 percent. For this reason, the chosen forecasting calculation is a double moving average with 3 moving.
\end{abstract}

\section{PENDAHULUAN}

Perusahaan pengolahan kelapa sawit merupakan salah satu produsen minyak goreng (olein) di Sumatera Barat, yang didistribusikan baik curah maupun sudah dikemas. Minyak goreng curah menguasai $75 \%$ pangsa pasar produksi di Indonesia dan sekitar 77,5\% rumah tangga di Indonesia menggunakan minyak goreng curah karena harganya yang lebih murah dibanding minyak goreng kemasan [1].

Kegunaan terbesar olein adalah sebagai minyak goreng (edible oil) yang bermanfaat sebagai penghantar panas, penambah rasa dan kalori pada saat proses memasak. Selain itu, olein memiliki produk turunan seperti shortenings dan margarine [2]. Shortenings merupakan turunan olein dengan kandungan minyak dan lemak $100 \%$, biasanya digunakan sebagai bahan baku buttercream, pembuatan roti tawar, hingga menambah rasa pada kue dan cake. Sedangkan margarine memiliki komposisi $80 \%$ oil serta $20 \%$ air. Margarin sangat umum DOI: http://dx.doi.org/10.52759/inventory.v2i2.53 digunakan sebagai salah satu bahan untuk memasak dan olesan roti.

Demand terhadap olein kedepannya diprediksi akan terus meningkat seiring bertmbahnya jumlah penduduk, meningkatnya Gross Domestic Product (GDP) dan juga karena melimpahnya ketersediaan bahan baku CPO di dalam negeri [3]. Fluktuasi demand konsumen terhadap olein menyebabkan perusahaan perlu memperkirakan penjualan di masa depan agar aktivitas produksi menjadi lebih efektif dan efisien. Perencanaan produksi menjadi aspek yang esensial karena aktivitas ini merencanakan berapa jumlah produk yang akan diproduksi, berapa dan apa saja bahan baku/material yang dibutuhkan, hingga mampu menggambarkan berapa kapaistas simpan yang harus disiapkan. Rencana produksi yang baik akan mampu merumuskan keputusan yang mengakomodir pertanyaan Mengapa, Apa, Siapa, Dimana dan Bagaiamana [4].

Peramalan merupakan salah satu tahap awal dari perencanaan produksi dimana di tahap ini suatu kondisi 
dimasa datang diperkirakan dari kondisi yang telah terjadi sebelumnya atau berdasarkan data historikal. Markidakis dalam [5] menyatakan bahwa peramalan dilakukan dengan tujuan untuk meminimalkan ketidakpastian, sehingga penentuan metode peramalan yang baik harus memiliki tingkat kesalahan ramalan kecil. Tujuan dari peramalan adalah menggunakan informasi sebaik-baiknya sebagai panduan aktivitas dimasa yang akan datang agar tujuan organisasi dapat tercapai, yang dalam penelitian ini yaitu aktivitas produksi.

[6] menjabarkan agar peramalan yang dilakukan dapat member hasil yang mendekati kondisi real, maka perlu untuk : menentukan tujuan dari peramalan, menentukan data yang akan digunakan, memilih metode peramalan yang sesuai, melakukan peramalan, mengihitung kesalahan peramalan yang terkecil lalu mengimplementasikan hasil peramalan untuk mengambil keputusan.

Penelitian yang dilakukan oleh [7] membandingkan metode peramalan single moving average dan single exponential smoothing. Hasil perhitungan tersebut menampilkan bahwa single moving average memiliki nilai kesalahan peramalan lebih kecil. Penelitian yang dilakukan [8] membandingkan metode peramalan single exponential smoothing dengan double moving average. Hasil yang didapat adalah metode double moving average memberikan kesalahan lebih kecil dibandingkan metode exponential smoothing.

Berdasarkan uraian diatas, dilakukan penelitian ilmiah untuk menghitung kebutuhan olein curah menggunakan double moving average di perusahaan pengolahan kelapa sawit, Sumatera Barat. Penelitian ini membandingkan perhitungan double moving average dengan nilai pergerakan 3, 4 dan 5. Hasil perhitungan masing-masing akan diverifikasi dengan menghitung tingkat kesalahan menggunakan metode Mean Absolute Percentage Error (MAPE). Hasil perhitungan diharapkan dapat memberi masukan kepada perusahaan pengolahan kelapa sawit dalam merencanakan kegiatan produksi olein.

\section{METODOLOGI}

Pada penelitian ini, data yang digunakan merupakan data historis penjualan olein di perusahaan pengolahan kelapa sawit sejak bulan Oktober 2020 hingga September 2021. Metode pengumpulan data dilakukan dengan observasi dan wawancara langsung kepada pihak perusahaan.

Observasi dilakukan dengan mencatat data hasil pengamatan langsung pada aktivitas pengeluaran olein dari perusahaan pengolahan kelapa sawit. Data yang dicatat hanya beberapa periode dan dalam satuan hari. Oleh karena itu, pencatatan didasarkan juga pada kartu keluar barang kemudian direkap menjadi data per bulan selama satu tahun. Selanjutnya adalah metode wawancara yaitu sebuah metode untuk memperoleh informasi secara langsung dari pihak yang memiliki pengetahuan, wawasan dan pengalaman terhadap hal yang ingin diketahui. Tanya jawab dilakukan kepada pelaksana dan penanggung jawab dalam proses pengeluaran olein.

Setelah diperoleh data penjualan olein selama rentang waktu 1 tahun, kemudian data tersebut diinputkan ke diagram pencar (scatter diagram) yang ditampilkan pada Gambar 1.

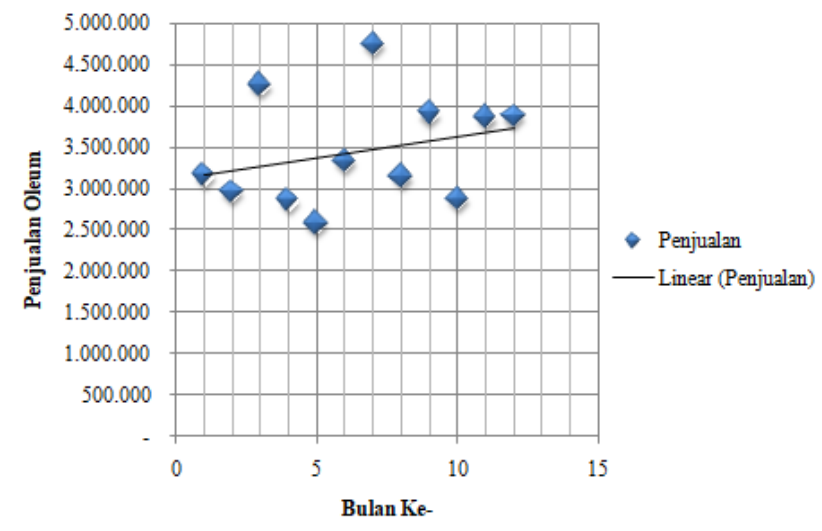

Gambar 1. Grafik Data Penjualan

Tabel 1. Jumlah Penjualan Olein Curah

\begin{tabular}{ccc}
\hline Tahun & Bulan & Penjualan (kg) \\
\hline \multirow{3}{*}{2020} & Oktober & 3.159 .380 \\
& November & 2.951 .569 \\
& Desember & 4.257 .000 \\
& Januari & 2.855 .280 \\
& Februari & 2.578 .530 \\
& Maret & 3.330 .790 \\
& April & 4.745 .008 \\
& Mei & 3.145 .908 \\
& Juni & 3.906 .976 \\
& Juli & 2.876 .096 \\
& Agustus & 3.862 .900 \\
& September & 3.870 .678 \\
\hline
\end{tabular}

(Sumber: perusahaan pengolahan kelapa sawit, 2021)

\section{Double Moving Average}

Metode peramalan double moving average merupakan perluasan dari metode single moving average, karena metode ini melakukan perhitungan single moving average sebanyak dua kali [9].

Metode double moving average adalah metode rata-rata bergerak, maksudnya adalah nilai rata-rata akan 
menggunakan data yang terbaru kemudian meniadakan data yang lama. Metode ini cocok untuk meramalkan data yang bersifat trend [10]. Dari gambar 1 terlihat bahwa data penjualan olein di perusahaan pengolahan kelapa sawit memiliki sebuah trend yang meningkat seiring berjalannya waktu, walaupun terdapat fluktuasi didalamnya.

Jika diketahui terdapat $N$ periode sebagai jumlah nilai pergerakan dan $X$ merupakan data aktual yang diinputkan pada perhitungan ramalan di setiap waktu $t$, maka perhitungan peramalan akan menggunakan data $X$ sebanyak $N$. Proses ini disebut dengan rata-rata bergerak dengan nilai pergerakan $N$. Penjelasan lebih lanjut perhitungan peramalan single moving average ditampilkan pada Tabel 2.

Tabel 2. Konsep moving avergae

\begin{tabular}{cc}
$\begin{array}{c}\text { Waktu } \\
\text { Pergerakan }\end{array}$ & \multicolumn{1}{c}{ Rata-rata bergerak } \\
\hline $\mathrm{N}=3$ & $\bar{X}=\frac{X_{t-2}+. X_{t-1}+X_{t}}{3}$ \\
$\mathrm{~N}=4$ & $\bar{X}=\frac{X_{t-3}+X_{t-2}+. X_{t-1}+X_{t}}{4}$ \\
$\mathrm{~N}=5$ & $\bar{X}=\frac{X_{t-4}+X_{t-3}+X_{t-2}+. X_{t-1}+X_{t}}{5}$ \\
\hline
\end{tabular}

Adapun langkah perhitungan peramalan double moving average adalah:

Menghitung Single Moving Average $\left(S^{\prime}{ }_{t}\right)$

$S^{\prime}{ }_{t}=\frac{X_{t}+X_{t-1}+\ldots+X_{t-N+1}}{N}$

Menghitung Double Moving Average ( $\left.{ }^{\prime}{ }^{\prime}{ }^{\prime}\right)$

$S^{\prime}{ }_{t}=\frac{S^{\prime}+S^{\prime} t-1+\ldots+S^{\prime} t-N+1}{N}$

\section{Menghitung konstanta a}

Konstanta a merupakan selisih antara single moving average dan double moving average.

$$
\begin{aligned}
a_{t} & =S^{\prime}{ }_{t}+\left(S^{\prime}{ }_{t}-S^{\prime \prime}{ }_{t}\right) \\
& =2 S^{\prime}{ }_{t}-S^{\prime \prime}{ }_{t}
\end{aligned}
$$

Menghitung slope $b$

Slope $b$ merupakan kecenderungan antara periode $t$ dengan periode $t+1$

$b_{t}=\frac{2}{N-1}\left(S_{t}^{\prime}-S^{\prime \prime}{ }_{t}\right)$

Menghitung peramalan m periode berikutnya $\left(F_{t+m}\right)$

$F_{t+m}=a_{t}+b_{t} m$

\section{Mean Absolute Percentage Error (MAPE)}

MAPE merupakan salah satu metode perhitungan kesalahan / error peramalan. Metode ini menghitung selisih antar data actual dengan hasil peramalan kemudian diabsolutkan selanjutnya dibagi dengan jumlah data yang ada. Hasil perhitungan MAPE ditampilkan dalam bentuk persen. Tujuan dari MAPE adalah mencari nilai perbandingan antara data aktual dengan hasil peamalan. Adapun formulasi MAPE adalah sebagai berikut [12]:

$M A P E=\left(\frac{100 \%}{n}\right) \sum_{t=1}^{n} \frac{\left|X_{t}-F_{t}\right|}{X_{t}}$

Diketahui $X_{t}$ adalah data aktual, dalam penelitian ini yaitu penjualan olein per bulan. $F_{t}$ adalah hasil peramalan pada periode $t$ dan $n$ merupakan jumlah periode peramalan yang dihitung. Kriteria dari nilai MAPE ditampilkan pada Tabel 3 [13].

Tabel 3. Kriteria nilai MAPE

\begin{tabular}{ll}
\hline Nilai MAPE & $\begin{array}{l}\text { Kriteria Kemampuan } \\
\text { Peramalan }\end{array}$ \\
\hline$<10 \%$ & Sangat Baik \\
$10 \% \leq 20 \%$ & Baik \\
$20 \% \leq 50 \%$ & Cukup Baik \\
$>50 \%$ & Buruk \\
\hline
\end{tabular}

(Sumber: Hajjah, 2020)

Semakin besar nilai MAPE maka semakin tidak akurat peramalan yang dilakukan. Semakin kecil nilai MAPE, menunjukan hasil peramalan semakin dapat dipercaya.

\section{HASIL DAN PEMBAHASAN}

Perhitungan peramalan double moving average penjualan olein di perusahaan pengolahan kelapa sawit dilakukan dengan nilai pergerakan 3, 4 dan 5. Kemudian hasil perhitungan ketiga ini dibandingkan dengan menghitung MAPE masing-masing.

\section{Perhitungan Double Moving Average (DMA) Dengan Pergerakan 3}

Peramalan $S^{\prime} t$ dimulai dari data ketiga, yaitu bulan Desember 2020. Karena untuk perhitungan $S^{\prime} t$ perode ketiga perlu menggunakan data $X_{1}, X_{2}$, dan $X_{3}$. Perhitungan peramalan tunggal menggunakan persamaan (1) dan peramalan ganda menggunakan persamaan (2). Data pada Tabel 1 diolah dengan kedua formulasi tersebut sehingga diperoleh hasil yang disajikan pada Tabel 4.

Berdasarkan persamaan (3) dapat di tentukan nilai konstanta $a$, untuk $t_{12}$ yaitu:

$$
\begin{aligned}
a & =2{S^{\prime}}_{t}-S^{\prime \prime}{ }_{t} \\
& =2(3.536 .558)-3.464 .958 \\
& =3.393 .359
\end{aligned}
$$

Selanjutnya perhitungan slope $b \begin{array}{lll}t_{12} & \text { menggunakan }\end{array}$ persamaan (4) 


$$
\begin{aligned}
b_{t} & =\frac{2}{N-1}\left(S_{t}^{\prime}-S^{\prime \prime}{ }_{t}\right) \\
& =\frac{2}{3-1}(3.536 .558-3.464 .958) \\
& =71.600
\end{aligned}
$$

Setelah konstanta $a_{12}$ dan slope $b_{12}$ dihitung, maka nilai peramalan periode ke $13 F_{12+1}$ dapat dihitung dengan persamaan (5).

$$
\begin{aligned}
F_{t+m} & =a_{t}+b_{t} m \\
F_{12+1} & =a_{12}+b_{12}(1) \\
& =3.393 .359+71.600(1) \\
& =3.393 .359 \mathrm{~kg}
\end{aligned}
$$

Dari hasil perhitungan doube moving average pergerakan 3 diperoleh bahwa jumlah penjualan olein pada bulan Oktober 2021 diperkirakan sebesar 3.393.359kg.

Tabel 4. Perhitungan Peramalan DMA Pergerakan 3

\begin{tabular}{cccc}
\hline $\mathbf{t}$ & Penjualan $(\mathbf{X})$ & $\boldsymbol{S}^{\prime} \boldsymbol{t}$ & $\boldsymbol{S}^{\prime \prime} \boldsymbol{t}$ \\
\hline 1 & 3.159 .380 & - & - \\
2 & 2.951 .569 & - & - \\
3 & 4.257 .000 & 3.455 .983 & - \\
4 & 2.855 .280 & 3.354 .616 & - \\
5 & 2.578 .530 & 3.230 .270 & 3.346 .956 \\
6 & 3.330 .790 & 2.921 .533 & 3.168 .807 \\
7 & 4.745 .008 & 3.551 .443 & 3.234 .415 \\
8 & 3.145 .908 & 3.740 .569 & 3.404 .515 \\
9 & 3.906 .976 & 3.932 .631 & 3.741 .547 \\
10 & 2.876 .096 & 3.309 .660 & 3.660 .953 \\
11 & 3.862 .900 & 3.548 .657 & 3.596 .983 \\
12 & 3.870 .678 & 3.536 .558 & 3.464 .958 \\
\hline (Sumber: Data diolah) & &
\end{tabular}

\section{Perhitungan Double Moving Average (DMA) Dengan Pergerakan 4}

Perhitungan peramalan double moving average pergerakan 4 menggunakan tata cara dan langkah yang sama dengan double moving average pergerakan 3 . Perbedaannya terletak pada data yang digunakan. Untuk DMA pergerakan 4 , perhitung $S_{t}{ }_{t}$ akan dimulai pada periode ke empat menggunakan data $X_{1}, X_{2}, X_{3}$ dan $X_{4}$. Pengolahan data dengan metode DMA pergerakan 4 ditampilkan pada Tabel 2.

Nilai konstanta $a$, untuk $t_{12}$ yaitu:

$$
\begin{aligned}
a & =2 S^{\prime}{ }_{t}-S^{\prime \prime}{ }_{t} \\
& =2(3.629 .163-3.631 .950) \\
& =3.634 .738
\end{aligned}
$$

Perhitungan slope $b_{12}$ sesuai persamaan (4) adalah:

$$
\begin{aligned}
& b_{t}=\frac{2}{N-1}\left(S^{\prime}{ }_{t}-S^{\prime \prime}{ }_{t}\right) \\
& 42 \text { Oktavia et al. }
\end{aligned}
$$

$$
\begin{aligned}
& =\frac{2}{4-1}(3.629 .163-3.631 .950) \\
& =-1.858
\end{aligned}
$$

Selanjutnya nilai peramalan perode ke $13 F_{12+1}$

$$
\begin{aligned}
F_{12+1} & =a_{12}+b_{12}(1) \\
& =3.634 .738-1.858(1) \\
& =3.629 .163 \mathrm{~kg}
\end{aligned}
$$

Dari hasil perhitungan doube moving average pergerakan 4 diperoleh bahwa jumlah penjualan olein pada bulan Oktober 2021 diperkirakan sebesar $3.629 .163 \mathrm{~kg}$.

Tabel 5. Perhitungan Peramalan DMA Pergerakan 4

\begin{tabular}{crcc}
\hline $\mathbf{t}$ & Penjualan $(\mathbf{X})$ & $\mathbf{S}^{\prime} \mathbf{t}$ & $\mathbf{S}^{\prime \prime} \mathbf{t}$ \\
\hline 1 & 3.159 .380 & - & - \\
2 & 2.951 .569 & - & - \\
3 & 4.257 .000 & - & - \\
4 & 2.855 .280 & 3.305 .807 & - \\
5 & 2.578 .530 & 3.160 .595 & - \\
6 & 3.330 .790 & 3.255 .400 & - \\
7 & 4.745 .008 & 3.377 .402 & 3.274 .801 \\
8 & 3.145 .908 & 3.450 .059 & 3.310 .864 \\
9 & 3.906 .976 & 3.782 .171 & 3.466 .258 \\
10 & 2.876 .096 & 3.668 .497 & 3.569 .532 \\
11 & 3.862 .900 & 3.447 .970 & 3.587 .174 \\
12 & 3.870 .678 & 3.629 .163 & 3.631 .950 \\
\hline (Sumber: Data diolah) & &
\end{tabular}

\section{Perhitungan double moving average (DMA) dengan pergerakan 5}

Hasil perhitungan $S^{\prime} t$ dan $S$ ''t metode double moving average pergerakan 5 ditampilakn pada Tabel 6 . Persamaan yang digunakan untuk menghitung konstanta $a$, slope $b$ dan peramalan Oktober $2021 F_{13}$ adalah persamaan (3), (4) dan (5) dengan penjabaran sebagai berikut

Nilai konstanta $a$, untuk $t_{12}$ yaitu:

$$
\begin{aligned}
a & =2{S^{\prime}}_{t}-S^{\prime \prime}{ }_{t} \\
& =2(3.532 .512 .3 .542 .678) \\
& =3.552 .845
\end{aligned}
$$

Perhitungan slope $b_{12}$ sesuai persamaan (4) adalah:

$$
\begin{aligned}
b_{t} & =\frac{2}{N-1}\left(S_{t}^{\prime}-S^{\prime \prime}{ }_{t}\right) \\
& =\frac{2}{5-1}(3.532 .512-3.542 .678) \\
& =-5.083
\end{aligned}
$$

Selanjutnya nilai peramalan perode ke $13 F_{12+1}$

$$
\begin{aligned}
F_{12+1} & =a_{12}+b_{12}(1) \\
& =3.552 .845-5.083(1) \\
& =3.547 .761 \mathrm{~kg}
\end{aligned}
$$


Tabel 6. Perhitungan Peramalan DMA Pergerakan 5

\begin{tabular}{cccc}
\hline $\mathbf{t}$ & Penjualan $(\mathbf{X})$ & $\mathbf{S}^{\prime} \mathbf{t}$ & $\mathbf{S}^{\prime \prime} \mathbf{t}$ \\
\hline 1 & 3.159 .380 & - & - \\
2 & 2.951 .569 & - & - \\
3 & 4.257 .000 & - & - \\
4 & 2.855 .280 & - & - \\
5 & 2.578 .530 & 3.160 .352 & - \\
6 & 3.330 .790 & 3.194 .634 & - \\
7 & 4.745 .008 & 3.553 .322 & - \\
8 & 3.145 .908 & 3.331 .103 & - \\
9 & 3.906 .976 & 3.541 .442 & 3.356 .171 \\
10 & 2.876 .096 & 3.600 .956 & 3.444 .291 \\
11 & 3.862 .900 & 3.707 .378 & 3.546 .840 \\
12 & 3.870 .678 & 3.532 .512 & 3.542 .678 \\
\hline
\end{tabular}

(Sumber: Data diolah)

Hasil peramalan menggunakan nilai pergerakan 3, 4, dan 5 memberi hasil yang berbeda. Hal ini dikarenakan data input rata-rata bergerak tiap nilai pergerakan tersebut berbeda. Untuk menentukan nilai pergerakan mana yang paling cocok digunakan, selanjutnya dilakukan perhitungan tingkat kesalahan peramalan dengan metode mean absolute percentage error (MAPE).

\section{Perhitungan Mean Absolute Percentage Error}

Persamaan (6) digunakan untuk menghitung error. Sebelumnya, ditentukan bahwa penentuan nilai peramalan sebelumnya akan menggunakan nilai $a_{12}$ dan $b_{12}$, sehingga nilai $\mathrm{m}$ akan diproprsikan. Misal, mencari peramaln di periode 11 maka formulasinya menjadi:

$F_{\text {september }}=F_{12-0}=a_{12}+b_{12}(0)$

$F_{\text {agustus }}=F_{12-1}=a_{12}+b_{12}(-1)$

$F_{\text {Juli }}=F_{12-2}=a_{12}+b_{12}(-2)$, dst

Perhitungan yang dilakukan ditampilkan pada tabel 7 dan menjadi input perhitungan MAPE dengan persamaan (6). Hasil pengolahan data di tabel 7 memperlihatkan periode peramalan yang dihitung berbeda tiap pergerakan. Kondisi ini dipengaruhi oleh periode yang digunakan, contohnya untuk pergerakan 3 maka pehitungan single moving average dimulai pada periode ke-3, kemudian perhitungan double moving average dilakukan pada periode ke-5. Kondisi ini ditampilkan pada Gambar 2.

Pada Gambar 2 hasil peramalan dengan nilai pergerakan 3,4 dan 5 di lambangkan dengan $F 3, F 4$, dan F5. Hasil peramalan double moving average pergerakan 3 dimulai dari periode 5, hasil DMA pergerakan 4 dari periode 7, dan hasil DMA pergerakan 5 mulai dari periode 9 .
Tabel 7. Hasil peramalan $t_{1}$ hingga $t_{12}$

\begin{tabular}{cccc}
\hline $\boldsymbol{t}$ & $\boldsymbol{F}$ (pergerakan & $\boldsymbol{F}$ (pergerakan & $\boldsymbol{F}$ (pergerakan \\
\hline 1 & 3) & 4) & 5) \\
2 & - & - & - \\
3 & - & - & - \\
4 & - & - & - \\
5 & 2.892 .162 & - & - \\
6 & 2.963 .762 & - & - \\
7 & 3.035 .361 & 3.644 .029 & - \\
8 & 3.106 .961 & 3.642 .171 & - \\
9 & 3.178 .560 & 3.640 .313 & 3.568 .094 \\
10 & 3.250 .160 & 3.638 .454 & 3.563 .011 \\
11 & 3.321 .759 & 3.636 .596 & 3.557 .928 \\
12 & 3.393 .359 & 3.634 .738 & 3.552 .845 \\
\hline (Sumber: Data diolah) & &
\end{tabular}

(Sumber: Data diolah)



Gambar 2. Perbandingan Data Penjualan dan Hasil Peramalan

Karena tujuan MAPE adalah untuk membandingkan data aktual dengan hasil peramalan, sehingga jumlah data yang dihitung akan berbeda tiap pergerakan. Jumlah data $n$ pergerakan 3 adalah 8 , jumlah data $n$ pergerakan 4 adalah 6 dan jumlah data $n$ pergerakan 5 adalah 4 .

Nilai $\sum|\mathrm{Xi}-\mathrm{Fi}| / \mathrm{Xi}$ untuk pergerakan 3 adalah 1,18411 dan disubstitusikan dengan persamaan (6) menjadi

$M A P E_{\text {rataan } 3}=\left(\frac{100 \%}{8}\right)(1,18411)=14,805 \%$

kemudian $\sum|\mathrm{Xi}-\mathrm{Fi}| \mathrm{Xi}$ untuk pergerakan 4 adalah 0,8426 dan disubstitusikan dengan persamaan (6) menjadi

$M A P E_{\text {rataan } 4}=\left(\frac{100 \%}{6}\right)(0,8426)=14,044 \%$

Selanjutnya untuk pergerakan 5 , hasil perhitungan $\sum \mid \mathrm{Xi}$ Fi|/Xi-nya adalah 0,4866 sehingga

$M A P E_{\text {rataan } 5}=\left(\frac{100 \%}{4}\right)(0,4866)=12,166 \%$

Berdasarkan perhitungan MAPE ketiga pergerakan, diperoleh hasil bahwa pergerakan 5 memiliki nilai error paling kecil yaitu 12\%. Hal ini berbeda Ketika dibandingkan dengan MAPE pergerakan 3 dan 4 yang 
berada di rentang 14\%. Berdasarkan Gambar 1. Terlihat bahwa data bulan ke-7 memiliki selisih paling besar dari garis trend data yang diolah. Persamaan garis trend data penjualan olein di perusahaan pengolahan kelapa sawit adalah

$y=51520 x+3 E+06$

Setelah dilakukan pengukuran titik data yang terletak paling jauh, dan ditemukan bahwa data tersebut adalah data $t_{3}$ dan $t_{7}$. Yang paling jauh datanya adalah $t_{7}$. Untuk itu, akan dilakukan perhitungan peramalan ulang dengan kondisi:

(1) Data $t_{7}$ akan dikeluarkan dan perhitungan ulang dilakukan untuk kemudian kembali dihitung MAPE tiap pergerakan -nya.

(2) Data $t_{3}$ dan $t_{7}$ akan dikeluarkan dan perhitungan ulang dilakukan untuk kemudian kembali dihitung MAPE tiap pergerakan -nya.

Hasil MAPE dari kedua kondisi di atas akan dibandingkan beserta hasil perhitungan awal. Berikut hasil perhitungannya:

Tabel 8. Perbandingan MAPE

\begin{tabular}{lccc}
\hline \multirow{2}{*}{ Uraian } & \multicolumn{3}{c}{ MAPE } \\
\cline { 2 - 4 } & Pergerakan Pergerakan & Pergerakan \\
& $\mathbf{3}$ & $\mathbf{4}$ & $\mathbf{5}$ \\
\hline Data lengkap & 14,805 & 14,044 & 12,166 \\
$t 7$ dihilangkan & 11,863 & 17,339 & 12,166 \\
$t 3$ dan $t 7$ & 11,350 & 17,318 & 12,166 \\
dihilangkan & & & \\
\hline
\end{tabular}

(Sumber: Data diolah)

Hasil perhitungan menampilkan bahwa kesalahan peramalan yang besar ditampilkan dari metode double moving average dengan nilai pergerakan 3 dan 4 . Akan tetapi, setelah dilakukan koreksi serta penghilangan data yang jauh dari garis linear, ditemukan bahwa tingkat kesalahan terbesar adalah double moving average dengan nilai pergerakan 4. Serta error terkecil ditampilkan oleh double moving average pergerakan 3 dengan nilai $11 \%$. Sesuai kriteria nilai MAPE, rentang error antara $10 \%$ hingga 20\% termasuk katgori peramalan yang baik. Sehingga perhitungan DMA pergerakan 3 diteruskan untuk 3 periode selanjutnya, yaitu Oktober 2021, November 2021 dan Desember 2021.

Tabel 9. Hasil peramalan DMA pergerakan 3

\begin{tabular}{ll}
\hline Bulan & Nilai \\
\hline Oktober & 3.464 .958 \\
November & 3.536 .558 \\
Desember & 3.608 .158 \\
\hline
\end{tabular}

(Sumber: Diolah sendiri)

\section{KESIMPULAN}

Hasil peramalan jumlah penjualan olein di perusahaan pengolahan kelapa sawit menampilkan bahwa hasil dengan pergerakan 3, 4 dan 5 memiliki hasil yang berbeda. Dengan dibandingkannya niai error MAPE diantara ketiganya, metode dengan pergerakan terkecil adalah double moving average dengan nilai pergerakan 3. Sehingga jumlah peramalan untuk periode selanjutnya adalah: $3.464 .958 \mathrm{~kg}$ olein di bulan Oktober 2021, $3.536 .558 \mathrm{~kg}$ olein di bulan November 2021 dan $3.608 .158 \mathrm{~kg}$ olein di bulan Desember 2021. Metode double moving average cukup baik untuk menghitung peramalan dengan data yang memiliki trend, tetapi data yang diolah sebaiknya cukup banyak agar trend tersebut dapat teroetakan dengan baik. Selain itu, data dengan fluktuasi tinggi sebaiknya dikeluarkan dai kelompok data terlebih daulu.

\section{DAFTAR PUSTAKA}

[1] Hasrul Abdi Hasibuan, et al. "Review standar minyak goreng sawit diperkaya karoten terkait fortifikasi vitamin A sebagai revisi SNI 01-37412002". Jurnal Standarisasi. Volume 16 (1), Maret 2014, Pages 65-76, https://js.bsn.go.id/index.php/standardisasi/article/ download/76/pdf

[2] Zelika Nidya Damarani, et al. "Pra-Desain Pabrik Refined Bleached Deodorized (RBD) Olein dari Crude Palm Oil (CPO)." Jurnal Teknik ITS. $\begin{array}{llll}\text { Volume } & 8 & \text { 2019, }\end{array}$ http://ejurnal.its.ac.id/index.php/teknik/article/vie w/41671.

[3] Titania Dwi Andini, et al. "Peramalan Jumlah Stok Alat Tulis Kantor di UD Achmad Jaya menggunakan metode double exponential smoothing." Jurnal Ilmiah Teknologi dan Informasia (ASIA). Volume 10 (1). February 2016, Peramalan Jumlah Stok Alat Tulis Kantor Di UD ACHMAD JAYA Menggunakan Metode Double Exponential Smoothing - CORE Reader.

[4] Humairo, et al. "Peramalan menggunakan metode double exponential smoothing dan verifikasi peramalan menggunakan grafik pengendali tracking signal." Jurnal Ilmu Matematika dan Terapan. Volume 14 (1), March 2020, https://core.ac.uk/download/pdf/322568286.pdf.

[5] Agustina Eunike et. al. "Implementation of system dynamic simulation method to optimize profit in supply chain network of vegetable product." Economics and Social of Fisheries and Marine Journal. Volume 1, April 2018, Pages 1-13. View article (google.co.id) . 
[6] Sulistyowati. Anggaran Perusahaan,Teori dan Praktika. Surabaya: Scopindo Media Pustaka, 2020, pp36-37.

[7] Laksana, Andreas Indra. "Perbandingan Metode Single Moving Average dan Single Exponential Smoothing dalam Pengembangan Sistem Peramalan Penjualan Mobil Baru." Universitas Sanata Dharma, Yogyakarta, 2017. 135314066_full.pdf (usd.ac.id)

[8] Irma Tri Ardhiani, et al. "Sistem pendukung keputusan pengadaan supplies dengan metode single exponential smoothing dan double moving average (studi kasus rumah sakit siti khodijah sepanjang)." SNASTI. 2009, Pages 235-243. https://repository.dinamika.ac.id/id/eprint/436/1/20 09-III-235.pdf

[9] Auli Fisty Noor Azizah. "Aplikasi mtode peramalan double moving average dan doubl exponential smoothing brown pada data migrasi kota Surabaya." Univrsitas Airlangga, Surabaya, 2015. https://repository.unair.ac.id/23909/

[10] Etri Pujiati, et al. "Peramalan dengan menggunakan metode double exponential smoothing dari brown (studi kasus : indeks harga konsumen (IHK) kota samarinda)." Jurnal Eksponesial. Volume 7 (1), May 2016 http://jurnal.fmipa.unmul.ac.id/index.php/exponen sial/article/download/23/5/

[11] Padrul Jana, et al. "Peramalan Kurs IDR terhadap USD menggunakan double moving averages dan double exponential smoothing." Jurnal Derivat. Volume 2 (2), December 2015, Pages 48-55. https://journal.upy.ac.id/index.php/derivat/article/v iew/132

[12] Icha Yulian. "Penerapan metode trend moment dalam forecasting penjualan produk CV. Rabbani Asyisa." Jurnal Teknologi dan Sistem Informasi. Volume 6 (2), April 2021, pages 193-200. https://jurnal.stmikroyal.ac.id/index.php/jurteksi/ar ticle/download/443/373

[13] Alyauma Hajjah, et al. "Analisis error terhadap peramalan data penjualan." Jurnal Teknologi Informasi. Volume 20 (1), February 2021, pages 19. https://docplayer.info/210298283-Analisiserror-terhadap-peramalan-data-penjualan-erroranalysis-toward-sales-data-forecasting.html 